\title{
Globe
}

Revue internationale d'études québécoises

\section{Jacques Beauchemin : L'histoire en trop. La mauvaise conscience des souverainistes québécois. Montréal, VLB, coll. " Études québécoises ", 2002}

\section{Jacques Pelletier}

Volume 6, numéro 1, 2003

URI : https://id.erudit.org/iderudit/1000699ar

DOI : https://doi.org/10.7202/1000699ar

Aller au sommaire du numéro

Éditeur(s)

Globe, Revue internationale d'études québécoises

ISSN

1481-5869 (imprimé)

1923-8231 (numérique)

Découvrir la revue

Citer ce compte rendu

Pelletier, J. (2003). Compte rendu de [Jacques Beauchemin : L'histoire en trop. La mauvaise conscience des souverainistes québécois. Montréal, VLB, coll.

"Études québécoises ", 2002]. Globe, 6(1), 174-176.

https://doi.org/10.7202/1000699ar d'utilisation que vous pouvez consulter en ligne.

https://apropos.erudit.org/fr/usagers/politique-dutilisation/ 


\section{Jacques Beauchemin}

\section{L'bistoire en trop. La mauvaise conscience}

des souverainistes québécois.

Montréal, VLB, coll. "Études québécoises ", 2002.

Le grand paradoxe de la question nationale au Québec, c'est que plus sa solution concrète paraît s'éloigner, plus les analyses qui la prennent en compte s'avèrent complexes, subtiles et ingénieuses. Elle est ainsi devenue depuis quelques années le foyer de réflexion privilégié des meilleurs intellectuels québécois dans le domaine des sciences sociales, des politologues aux sociologues, en passant par les historiens et les philosophes qui ne cessent d'écrire et de publier de savantes analyses à son sujet.

Bien que nombreuses et apparemment diversifiées, les interprétations des nouveaux "penseurs de la nation ", lorsqu'on les regarde de plus près, présentent une singulière parenté, des airs de famille qui trouvent leur fondement dans un refus commun des analyses de Fernand Dumont, considéré comme le principal porte-parole d'un nationalisme jugé ethnique et dépassé, incapable de rendre compte des réalités contemporaines du Québec. Ce refus, on le trouve aussi bien derrière la thèse du nationalisme sociopolitique défendue par Michel Seymour que derrière le projet de francophonie nord-américaine proposé par Gérard Bouchard et, à un moindre degré, derrière la célébration de l'ambivalence canadienne-française évoquée - et survalorisée - par Jocelyn Létourneau.

Contrairement à ces analystes, dont le point de vue est devenu hégémonique au cours des dernières années, Jacques Beauchemin estime qu'il faut effectuer un retour à la pensée de Fernand Dumont pour comprendre la dimension historique et communautaire de la question nationale. La traiter en faisant abstraction de son enracinement historique, c'est se méprendre sur sa signification et son enjeu véritables.

C'est ainsi qu'en privilégiant l'immédiatement contemporain, Michel Seymour, par exemple, rencontre une impasse, n'arrivant pas à associer un groupe social spécifique au règlement de cette question et rendant donc sa réalisation fort aléatoire. De même, si le projet d'une francophonie nord-américaine de Gérard Bouchard peut satisfaire les aspira- 


\section{RECENSIONS}

tions linguistiques de la nation franco-québécoise, on ne voit pas trop en quoi la souveraineté rencontrerait des attentes plus larges fondées sur un sentiment d'appartenance communautaire réduit à peu de choses et qui ne saurait, pour autant, pleinement légitimer ce projet. Quant à Jocelyn Létourneau, si sa pensée s'apparente par moments à celle de Fernand Dumont, il n'en tire pas les mêmes conclusions politiques, faisant de l'ambivalence et de l'irrésolution des vertus civiques et politiques qui renvoient aux calendes grecques son éventuelle - et à vrai dire non souhaitable, de son point de vue - résolution.

Chez ces essayistes et chez bien d'autres qui partagent peu ou prou leurs positions, il y aurait, dissimulée derrière leur évidente volonté de modernisation de la question nationale, une "mauvaise conscience " qui les empêcherait de pleinement reconnaître les fondements historiques et communautaires du nationalisme franco-québécois dont on redoute les possibles dérives ethnicistes. Pour éviter ce danger, on réduit donc la portée de ce nationalisme amputé, en aval, de ses fondements historiques et culturels et, en amont, d'un projet mobilisateur tourné vers l'avenir.

Ce nationalisme révisé, prétendument civique, n'a ainsi plus grandchose à voir avec le vieux nationalisme canadien-français, fondé sur le désir de survivance, ce qui est une bonne chose, ni même avec le néonationalisme des années 1960 , axé sur une volonté de libération nationale et sociale, ce qui est une beaucoup moins bonne chose. En effet, c'est l'effacement de cette perspective qui peut largement expliquer, à mon avis, le blocage actuel, le sur-place débilitant qui caractérise la présente conjoncture. Jacques Beauchemin a donc raison d'insister sur la fécondité de la problématique de Fernand Dumont dont le supposé dépassement conduit à un évident cul-de-sac. Seule la prise en considération de l'histoire du groupe socioculturel franco-québécois peut en effet relancer la lutte pour la libération nationale.

Cela dit, ce n'est pas sur la nécessité de cette lutte qu'insiste l'auteur en conclusion de son ouvrage, mais plutôt sur l'obligation qu'il y aurait de parvenir à un compromis, à une solution " raisonnable "et "modérée " satisfaisant chacune des composantes de la société québécoise, y compris, bien sûr, le groupe franco-québécois. Mais si ce "compromis * et la grande "réconciliation" qu'appelle Beauchemin dans une rhétorique s'apparentant sur ce point à celle de Michel Seymour n'étaient pas 
possibles, faudrait-il du coup renoncer à la lutte de libération nationale? Assez curieusement, dans cette conclusion qui paraît en retrait par rapport aux analyses fort pertinentes qui la précèdent, tout se passe comme si l'auteur était tout à coup saisi lui-même par le malaise que son essai visait pourtant à dissiper! Comme quoi on ne se débarrasse pas facilement de la "mauvaise conscience " et de la culpabilité crucifiante qui l'accompagne lorsqu'on est franco-québécois d'héritage canadienfrançais; et il ne suffit manifestement pas de l'épingler pour en être débarrassé.

Jacques Pelletier

Université du Québec à Montréal

\section{Jean-Christian Pleau}

La révolution québécoise. Hubert Aquin

et Gaston Miron au tournant des années soixante.

Montréal, Fides, 2002.

Le paratexte annonce un ouvrage plutôt décapant, mû par le désir de relire "l'idée de "Révolution tranquille" "et de retrouver ce à quoi nous rend aveugles cette formule consacrée dont on ne saisit plus aujourd'hui " la valeur initiale de paradoxe ", à savoir le souhait, partagé par les intellectuels québécois des années 1960, d'une véritable révolution, dans ce qu'elle représentait de contraire à la tranquillité : "La Révolution tranquille, c'est en somme ce qui frappe de non-lieu la Révolution tout court " (p. 8). Ce n'est toutefois pas la pensée révolutionnaire à proprement parler qui occupe Jean-Christian Pleau, mais une partie de la "pensée politique " d'Hubert Aquin et de Gaston Miron, et plus particulièrement celle qu'élaborent l'essai "La fatigue culturelle du Canada français " et le poème "L'homme agonique ". Publiés en 1962 et en 1963 , ces deux " textes majeurs " (p. 11) sont choisis parce qu'ils correspondent au début de la " maturité " des deux écrivains et " au moment où la question de l'indépendance commen[ce] à occuper le premier plan de l'actualité " (p. 11). En deux chapitres, respectivement consacrés à Aquin et à Miron, l'étude se donne pour objets les influences intellectuelles et politiques des deux écrivains, les idées et leurs utilisations antérieures, l'inscription des textes dans leur contexte de rédaction et dans leur 